\title{
Correction to: The nucleocapsid protein of rice stripe virus in cell nuclei of vector insect regulates viral replication
}

\author{
Wan Zhao ${ }^{1,2}$, Junjie Zhu ${ }^{1,2}$, Hong Lu ${ }^{1,2}$, Jiaming Zhu ${ }^{1,2}$, Fei Jiang ${ }^{1,2}$, Wei Wang ${ }^{1,2}$, Lan Luo ${ }^{1,2}$, Le Kang ${ }^{1,2}$, \\ Feng Cui ${ }^{1,2 \bowtie}$ \\ ${ }^{1}$ State Key Laboratory of Integrated Management of Pest Insects and Rodents, Institute of Zoology, Chinese Academy of \\ Sciences, Beijing 100101, China \\ 2 CAS Center for Excellence in Biotic Interactions, University of Chinese Academy of Sciences, Beijing 100049, China \\ $\square$ Correspondence: cuif@ioz.ac.cn (F. Cui)
}

\section{CORRECTION TO: PROTEIN CELL \\ https://doi.org/10.1007/s13238- \\ 021-00822-1}

In the original publication of the article the fill color and the border color of the histograms in Fig. $3 \mathrm{~A}$ (dsGFP and dsIMPa1) and Fig. 3B were incorrect. Also, the schematic plot of the $\mathrm{N}$ fragment of NP in Fig. 2D was not clear enough. The correct Figs. 2 and 3 are provided in this correction. 
A
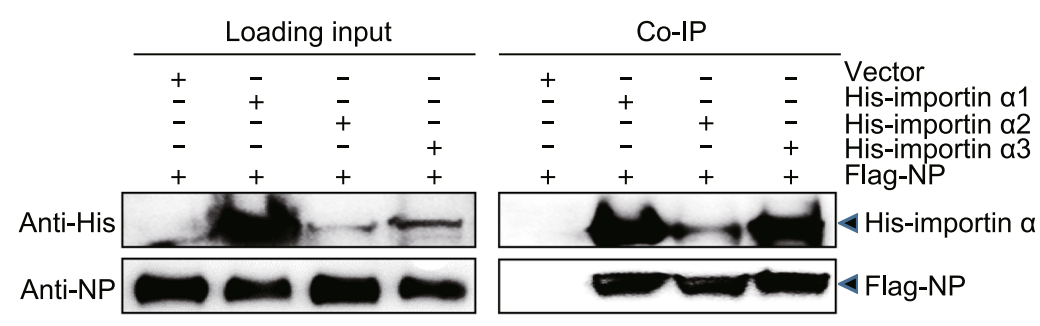

0
0
$\infty$
$e$
0
0
0
0
0

B
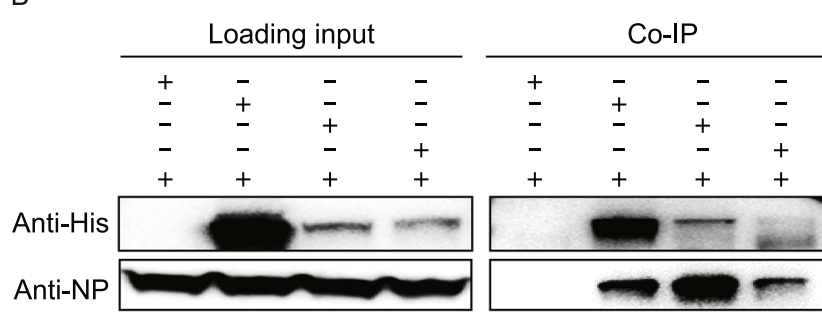

E
Vector

His-importin a1

His-importin a2

His-importin a 3

Viruliferous insects

4 His-importin a

$4 N P$
C

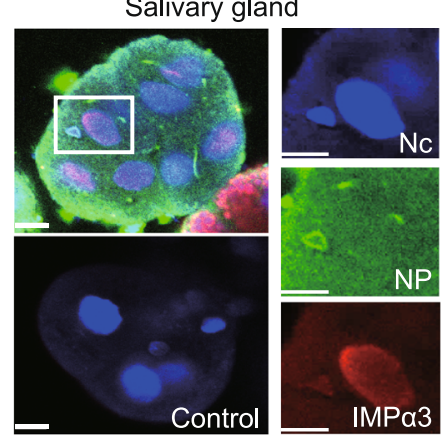

Midgut
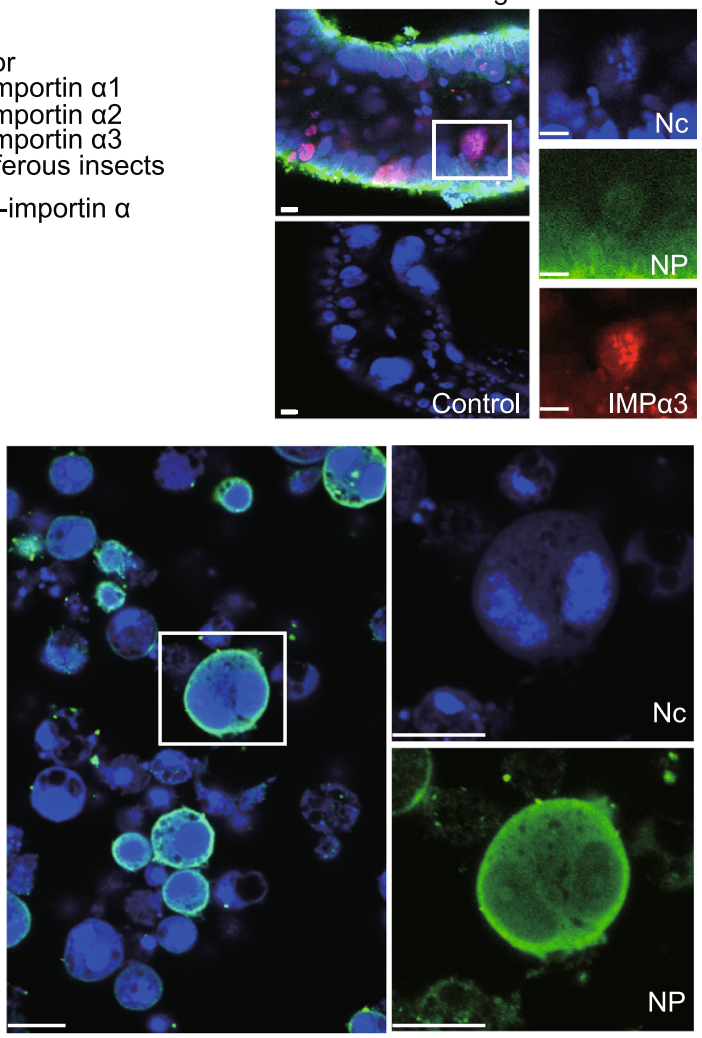

F

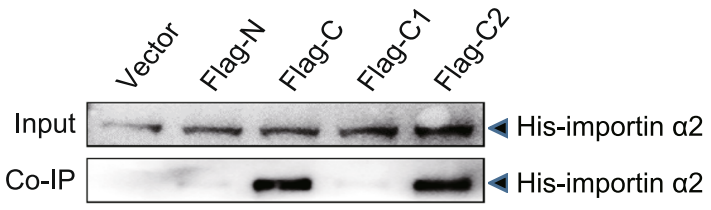

\begin{tabular}{|c|c|c|c|}
\hline & \multicolumn{3}{|c|}{ NLS } \\
\hline NP (322 aa) & A & & $\bar{D}$ \\
\hline$N(1-165$ aa $)$ & & & \\
\hline C (166-284 aa) & $A$ & & $\mathrm{D}$ \\
\hline C1 (166-193 aа) & $0^{\circ}$ & & \\
\hline C2 (204-284 aа) & & & \\
\hline
\end{tabular}

Nc

c
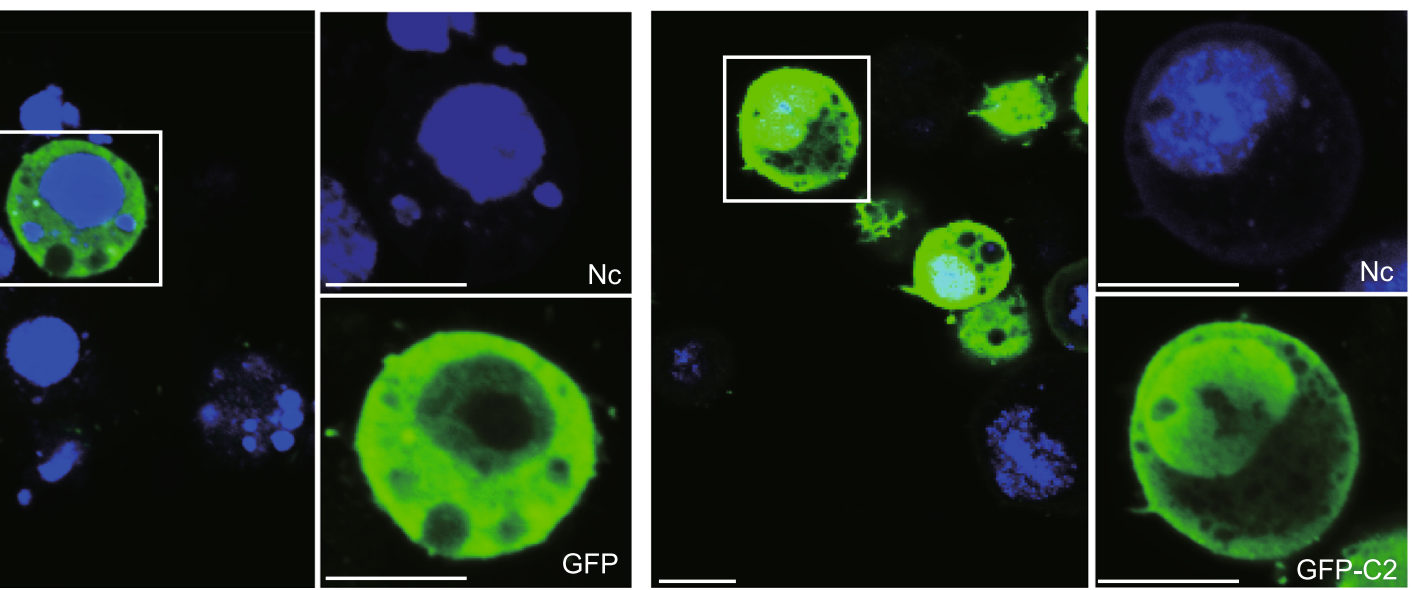
Figure 2. RSV nucleocapsid protein interacts with importin a proteins via. the nuclear localization signal. (A) Recombinantly expressed RSV nucleocapsid protein (NP) with a Flagtag binds three recombinantly expressed His-importin a proteins in the co-immunoprecipitation (Co-IP) and Western blot assay. The expression products from the $\mathrm{pET} 28 \mathrm{a}$ vector were used as a negative control. (B) Three recombinantly expressed His-importin a proteins pulled down the NP from viruliferous planthoppers in the Co-IP and Western blot assay. The expression products from the pET28a vector were used as a negative control. (C) Colocalization of importin $\alpha 3$ and NP examined in the salivary gland and midgut cells via immunohistochemistry analysis. The green signal is from an Alexa Fluor 488-labeled anti-NP monoclonal antibody. The red signal is from an Alexa Fluor 594-labeled anti-importin a3 (IMPa3) polyclonal antibody. The boxed region is enlarged and shown in three different panels on the right side. The samples without the treatment of primary antibodies are shown as negative controls. (D) Co-IP and Western blot assay for the interaction between the recombinantly expressed Flag-N, Flag-C, Flag-C1, or FlagC2 fragments of NP and His-importin a2. Motifs A, B, C and D comprise the putative nuclear localization signals (NLS). The overlapping amino acid residues shared by the motifs are marked in yellow. The expression products from the pET28a vector were used as a negative control. (E) Immunohistochemistry analysis of the subcellular location of expressed NP in S2 cells. The green signal is from an Alexa Fluor 488-labeled antiNP monoclonal antibody. The boxed region is enlarged and shown in two different panels on the right side. $(F)$ Subcellular location of expressed GFP and the GFP-C2 fragment in S2 cells was observed. The boxed region is enlarged and shown in two different panels on the right side. Scale bars in $2 \mathrm{C}, 2 \mathrm{E}$, and $2 \mathrm{~F}: 10 \mu \mathrm{m}$. The blue signal is the nuclei $(\mathrm{Nc})$ stained with Hoechst. 


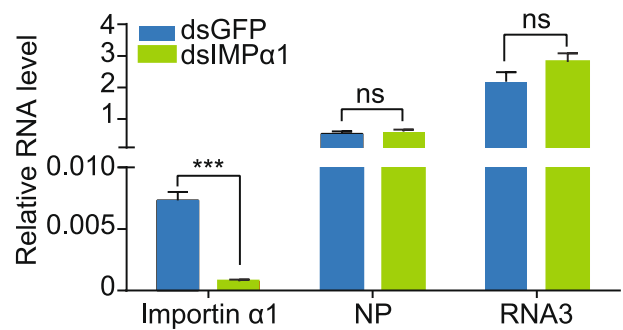

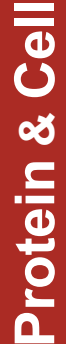
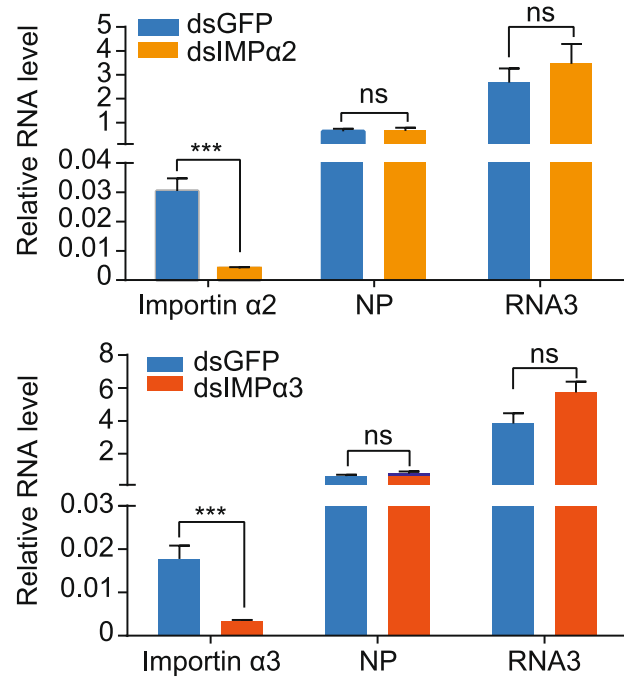

C
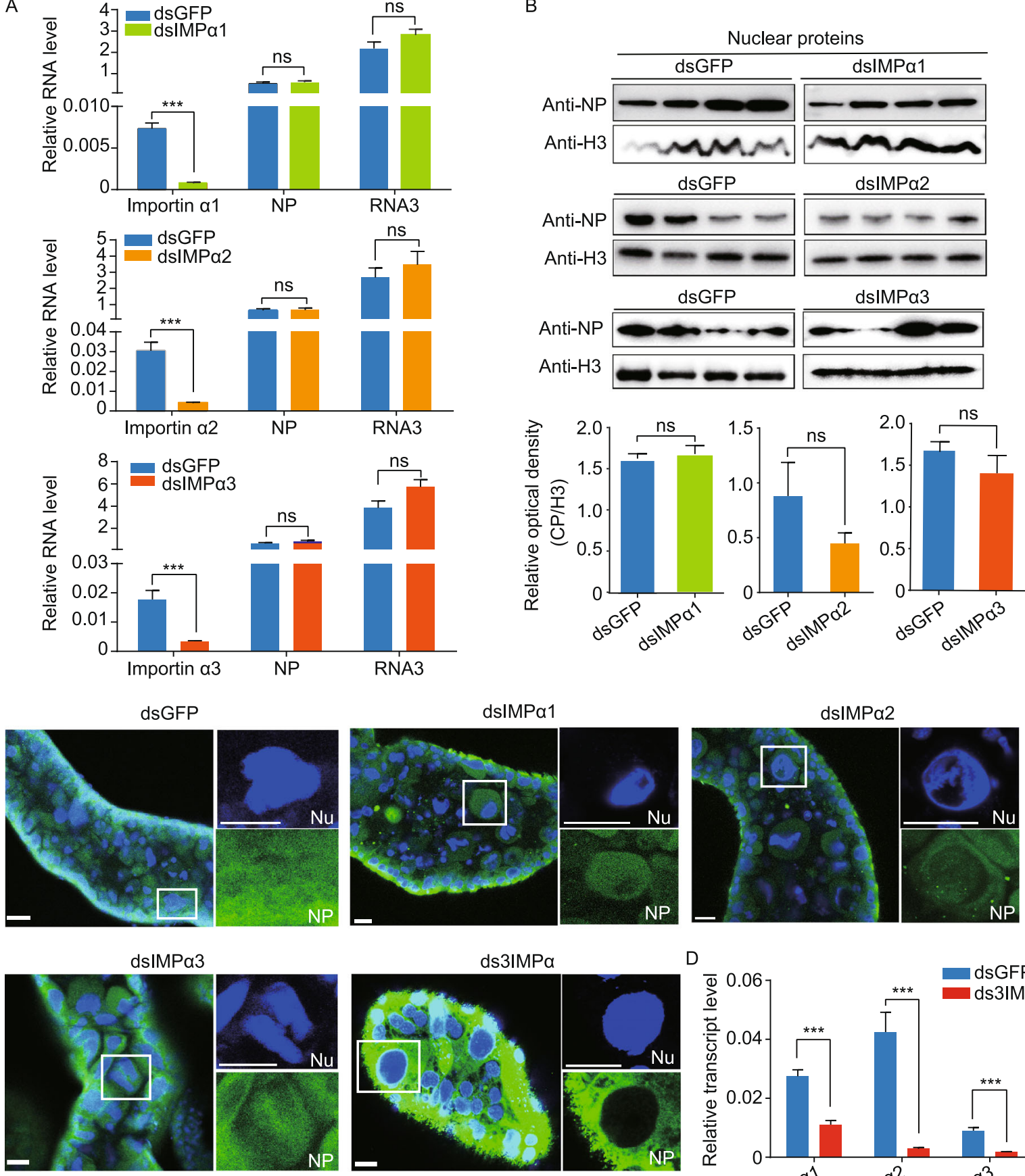

E
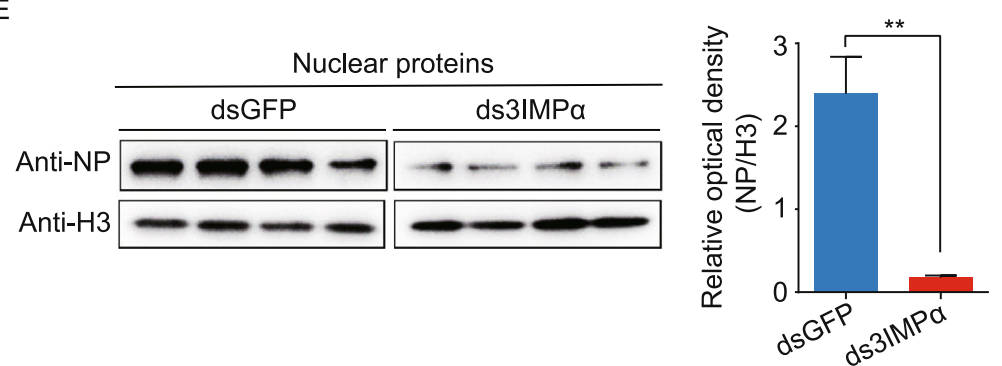

F
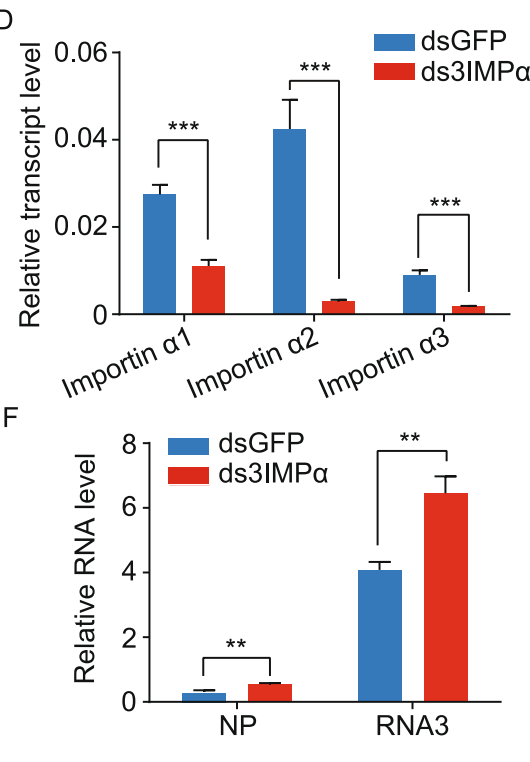
Figure 3. Inhibition of NP nuclear entry significantly promotes RSV accumulation in planthoppers. (A) Relative RNA levels of RSV NP and genomic RNA3 $7 \mathrm{~d}$ after the injection of dsRNA of importin $\alpha 1$ (dsIMPa1), importin $\alpha 2$ (dsIMPa2), importin $\alpha 3$ (dsIMPa3), or GFP (dsGFP), as measured by quantitative realtime PCR (qPCR). The RNA levels of NP and RNA3, and the transcript levels of importin $\alpha$ genes are normalized to that of EF2. (B) The nuclear accumulation of NP in the nuclear protein extracts of viruliferous planthoppers after the injection of dsIMPa1, dsIMPa2, dsIMPa3 or dsGFP for $7 \mathrm{~d}$, as assessed by Western blot assay. NP was detected using a monoclonal anti-NP antibody. The reference protein for the nuclear proteins was histone $\mathrm{H} 3$, which was detected using a monoclonal anti$\mathrm{H} 3$ antibody. Four independent replicates are shown for each group. The relative optical densities of NP to that of $\mathrm{H} 3$ were calculated. (C) Immunohistochemistry analysis of the subcellular location of NP in the midgut cells after the injection of dsIMPa1, dsIMPa2, dsIMPa3, a mixture of dsRNA of the three importin a genes (ds3IMPa), or dsGFP for $7 \mathrm{~d}$. NP was detected using a monoclonal anti-NP antibody. The blue signal is the nuclei (Nc) stained with Hoechst. The boxed region is enlarged and shown in two different panels on the right side. Scale bars: $20 \mu \mathrm{m}$. (D) The relative transcript levels of importin $\alpha 1, \alpha 2$ and $\alpha 3$ after the injection of ds3IMPa or dsGFP for $7 \mathrm{~d}$ measured by qPCR. (E) Nuclear accumulation of NP in the nuclear protein extracts of viruliferous planthoppers after the injection of ds3IMPa or dsGFP for $7 \mathrm{~d}$, as assessed via Western blot assay. Four independent replicates are shown for each group. The relative optical densities of NP to that of $\mathrm{H} 3$ are calculated. (F) Relative RNA levels of RSV NP and genomic RNA3 after injection of ds3IMPa or dsGFP for $7 \mathrm{~d}$ measured by qPCR. ns, no significant difference. ${ }^{* \star} P<0.01$. ${ }^{* * *} P<0.001$.

\section{OPEN ACCESS}

This article is licensed under a Creative Commons Attribution 4.0 International License, which permits use, sharing, adaptation, distribution and reproduction in any medium or format, as long as you give appropriate credit to the original author(s) and the source, provide a link to the Creative Commons licence, and indicate if changes were made. The images or other third party material in this article are included in the article's Creative Commons licence, unless indicated otherwise in a credit line to the material. If material is not included in the article's Creative Commons licence and your intended use is not permitted by statutory regulation or exceeds the permitted use, you will need to obtain permission directly from the copyright holder. To view a copy of this licence, visit http:// creativecommons.org/licenses/by/4.0/. 